\title{
El Estado y la nación en la era tecnológica
}

\author{
The State and Nation in the Technological Era
}

Ander Gurrutxaga Abad

Universidad del País Vasco / Euskal Herrilko Unibertsitatea

\section{RESUMEN}

En la actualidad, el momento histórico por el que atraviesa el Estado-Nación hay que entenderlo tomando en consideración los efectos combinados del proceso de globalización y el cambio tecnológico que tiene hoy su máximo exponente en lo que se ha llegado a denominar como la $4^{\text {a }}$ Revolución Industrial, junto al cansancio del Leviatán, provocado por la actividad irregular de más de tres siglos en los países del Centro Occidental. Mi tesis es que no se visualiza el final de los discursos nacionales ni la crisis de los referentes de la tradición estatal sino la configuración del poder político donde lo macro -grandes regiones políticas, organismos internacionales, corporaciones multinacionales-; lo meso (regiones y movimientos productos de la descentralización del poder político estatal o la contestación interna al centro político "incuestionable"); y lo micro poderes regiones y nacionalidades "periféricas"- pugnan por la construcción de la geometría variable que presenta al poder político del Estado enclavado en múltiples redes que discurren por instituciones de países y regiones interdependientes.

PALABRAS CLAVE: Estado-Nación, Globalización, Cambio Tecnológico, Modelos de Capitalismo. 


\section{ABSTRACT}

At the moment, the historical period that the Nation-State is living must be understood taking into account the combined effects of the globalization process and the rapid technological change, that today has its greatest exponent in what has come to be called the 4th Industrial Revoluction, together with the the Fatigue of Leviathan, caused by the irregular activity of more than three centuries in the Western countries. The main argument is that we are not whitnessing the end of national discourses, nor the crisis of the traditional institutions of the State, but the configuration of a new distribution of political power. This new configuration is characterized by new correlations between the institutional forces at the macro level -large political regions, international organzation, multinational corporations-, the regionalization process at the meso level -the increasing relevance of regions resulting of the decentralization of the political and economical power of the State-, and the movements at the micro level -pheripheral regions and nationalities-. The result is a variable geometry that show us that the political power of the State is now embedded in a amplified network of institutions that are defining the capabilities of political action.

KEY WORDS: Nation-State, Globalization, Technological Change, Models of Capitalism

\section{INTRODUCCIÓN}

El punto de partida del artículo es que la situación del Estado- Nación hay que entenderla desde los efectos combinados del proceso de globalización, la era tecnológica que tiene hoy su parada en la 4a Revolución Industrial y el cansancio de Leviatán provocado por la actividad de más de tres siglos en los países del Centro Occidental.

Sostengo las siguientes hipótesis; i) las transformaciones socioeconómicas de las últimas décadas provocan que exista la asimetría entre los Estados respecto a la autoridad que ejercen en la sociedad, la economía, la cultura y la política. La auctoritas estatal se debilita y las razones las encuentro en las consecuencias del cambio tecnológico, financiero y en la situación de los mercados gracias a la integración de las economías nacionales en la economía global. El recorrido que proponía S. Rokkan (2018) está condicionado por las transformaciones de las tres últimas décadas que proceden de la mano de la revolución tecnológica y la 
globalización (Rodrik 2012); ii) los cambios estructurales tienen relación con la reconfiguración de los supuestos sobre los que el Estado-Nación fundamentó el desarrollo histórico y la legitimidad de la praxis (sean la soberanía, el territorio, la frontera, la defensa del mercado nacional, la capacidad para acuñar moneda, la identidad nacional o la producción de lealtades); iii) la nación no desaparece, se acomoda a los espacios desde donde la globalización, las nuevas conexiones entre países, sociedades y regiones, la ley de los flujos y el imperativo tecnológico la sitúan como la presencia imprescindible del tiempo histórico; iv) los referentes tradicionales - sean la soberanía, el territorio, la frontera o el monopolio de la violencia-, son puestos en cuestión, disputados por agencias y sometidos a escrutinio radical.

El concepto "esconde" y, a la vez, proclama los procesos que se reconocen en la interdependencia. La conectografía (Khanna 2016) mantiene la nación, pero el "compañero" de los últimos siglos, el Estado debe reinventarse a la luz de los requerimientos del poder tecnológico, la globalización, la "asiatización" del mundo y la fatiga de materiales de los últimos siglos. Mi tesis es que no se visualiza el final de los discursos nacionales ni la crisis de los referentes de la tradición estatal sino la configuración del poder político donde lo macro grandes regiones políticas, organismos internacionales, corporaciones multinacionales-; lo meso (regiones y movimientos productos de la descentralización del poder político estatal o la contestación interna al centro político "incuestionable"); y lo micro poderes -regiones y nacionalidades "periféricas"- pugnan por la construcción de la geometría variable que presenta al poder político del Estado enclavado en múltiples redes que discurren por instituciones de países y regiones interdependientes, múltiples centros, la incertidumbre y las tensiones que promueven el trabajo conjunto de la revolución tecnológica, los procesos de la globalización, las miradas hacia otras regiones del mundo y el desgaste del poder político en los tres últimos siglos.

\section{LAS NUEVAS CONDICIONES DEL ESTADO-NACIÓN}

En los análisis que se ocupan de la cuestión destaca un punto: los cambios contemporáneos, en especial la revolución tecnológica y la globalización, debilitan la concepción tradicional del Estado-Nación. Cosa distinta es encontrar coincidencias en los diagnósticos o conocer las causas y las circunstancias de los cambios que lo transforman. 


\section{EL PODER DE LA TECNOLOGÍA}

La era tecnológica promueve el mundo de redes, conectado e interconectado, sumido en el poder de la aceleración y en el universo de flujos. Hay condiciones para estos hechos: 1) la ruptura del pacto suscrito en la edad de oro del desarrollo económico europeo-décadas de los cincuenta del siglo XX hasta los ochentadonde los procesos económicos de la sociedad industrial clásica aseguran el pleno empleo, se integran en el paradigma basado en la movilidad social ascendente y en la gestión del marco, a veces precario, de seguridad. Detrás de la generalización de las nuevas tecnologías y la traslación a los universos de la producción, el pacto sufre para mantener las promesas entre los sectores sociales que quieren acceder por primera vez al empleo y entre los alejados del centro de operaciones de las necesidades laborales que emiten la sabiduría tecnológica y el depósito de conocimiento que pone en funcionamiento la revolución digital. La sociedad del conocimiento replantea la estructura del trabajo, erige la incertidumbre, la desigualdad, la movilidad descendente y las transformaciones de la estructura social como arcanos de las consecuencias de su éxito. Las agencias que vinculan individuos, roles e instituciones "sagradas" padecen "fatiga de materiales". La definición cambia de sentido y algunos conceptos como los de vida propia, individuo reflexivo, emprendedor o creatividad individual son empleados, pero ya en el marco social cargado de incertidumbre (Bauman y Bordoni 2016).

Hay una demanda de clarificación de los sentidos del Estado-Nación. Éste sufre por cuatro hechos: i) la complejidad de las funciones que se le encomiendan. Incrementa la presencia en cada vez más ámbitos, se ocupa de muchas funciones, desarrolla los instintos de supervivencia desde lugares y caminos que no había explorado en otro tiempo. La paradoja es evidente, el incremento de la presencia provoca "necesidad de más presencia", pero no crecen por igual, ni con la misma rapidez, los instrumentos ni las posibilidades para gestionar el grado de complejidad; ii) algunas de las funciones del Estado revisan los recursos empleados en la financiación de las instituciones de las que se hace cargo. Se citan el endeudamiento y la deuda pública como dos de los motivos implícitos de la fatiga de materiales que cuestionan la viabilidad del Estado (Streeck 2016); iii) la integración simbólica se asocia con la capacidad material del Estado para resolver los problemas de la ciudadanía. N. Luhmann (1993) escribe que el efecto de compensación es la función básica del Estado y, a la vez, el condicionante de la legitimidad en contextos del bienestar. El grado de penetración en la sociedad civil se vehiculiza mediante los símbolos que emplea que otorgan confianza y credibilidad a las funciones latentes y manifiestas. Si las primeras se debilitan, las 
segundas se hacen más necesarias, pero es difícil sostener la capacidad de la simbología estatal-banderas, himnos, discursos comunitarios, etc-; iv) La organización territorial sufre para mantenerse porque la gestión del territorio afecta a la relación entre los aspectos micro, meso y macro. Las competencias de las instituciones regionalizadas, federalizadas o autonómicas entran en colisión con el ejercicio tradicional de los poderes del Estado Nación y con las referencias macro, propias de las organizaciones supracomunitarias -por ejemplo, la UE-.

\section{EL ESTADO EN SU LABERINTO: DISONANCIAS DE LOS PROCESOS}

El panorama descrito se relaciona con dos grandes transformaciones que le afectan; i) el tránsito desde la sociedad industrial a la del conocimiento; ii) la crisis económica de origen financiero que se propaga, afecta y penetra en la vida diaria de los ciudadanos desde el año 2008. La economía, en general, propulsada por la interconexión y los efectos de la globalización es el hecho más significativo por la capacidad para inundary desordenar lo "que toca".

La combinación de la innovación tecnológica con la integración económica internacional da lugar a la creación de nuevas redes. Desde mediados de la última década del siglo pasado, programadores informáticos y diseñadores de futuro coinciden en la visión donde confían en el "cerebro global" y el orden de los ordenadores para implantar los nuevos sentidos a la complejidad de las redes. Las posibilidades de la Singularidad abren paso a la transformación cámbrica que, según "la oficina de futurólogos", provoca la nueva inteligencia colectiva. La mirada romántica contrasta con la dimensión empírica de la utopía. Ni la complejidad horizontal ni los usos de la democratización de la política dicen que "todo lo posible es posible". El cuadro de la digitalización y de la economía que la sostiene amplifica sus efectos más allá de los aspectos sociotécnicos. Los territorios donde se sigue mejor el poder de la economía digital y el gobierno horizontal son en las consecuencias que depara, éstas no están en la vida que describen las utopías tecnológicas ni tampoco en el optimismo fabril de los constructores de la Industria 4.0 o la Fabricación Avanzada. Si se quiere conocer en profundidad qué es, cómo, por qué y para qué del poder tecnológico hay que seguir el cuadro de disonancias y las consecuencias no previstas que promueve.

En la obra "Capitalismo Big Tech", E. Morozov (2018) describe el orden industrial desde la hegemonía del imperio tecnológico y la ocupación del espacio productivo por las nuevas tecnologías. Desde este punto de vista, lo nuevo está claro: "las big tech se apoderan del recurso o servicio más valioso del momento (la inteligencia artificial- IA-) y el resto de la sociedad y de la economía deben 
encontrar la forma de introducirlo en sus actividades, a través de estas empresas y bajo las condiciones que estas quieren imponer".

A. Deaton (2016) celebró con la tesis del "gran escape" el tema clave de que hay que hacer para crear marcos explícitos que fomenten el desarrollo económico y fomenten la movilidad social ascendente. La explicación que ofrece quizá fue posible hace algunas décadas, pero ahora no puede ser, no al menos de manera tan singular, porque uno de los dramas de la disonancia laboral es la carencia de oportunidades, caminos y carreteras a las que entrar y mantenerse con el paso del tiempo. El "descubrimiento" es que la revolución digital promueve disonancias y maneras distintas de entender la construcción del empleo y la vida laboral, sin ofrecer otras rutas de acceso cuando no se dispone del conocimiento tecnológico y sólo dispone del barniz de los buenos consejos donde la conciencia del constructor de pirámides tecnológicas deposita buenos propósitos pero nada o casi nada es posible porque los cursos laborales no están claros, tampoco los trayectos que deben seguirse ni los requerimientos del acceso. Las "respuestas" siguen la autopista que promueve la sociedad auxiliar que se adhiere al denominado sector servicios, a los trabajos poco cualificados, mal pagados, temporales y escaso recorrido a la hora de construir el itinerario vital de vida y la biografía individual. El resultado es la "auxiliarización" de los trabajos fundamentales que dependen de la sociedad tecnológica de la $4^{\text {a }}$ Revolución Industrial.

Decía R. Sennett (2001) en La corrosión del carácter sobre el mundo del trabajo: "nada a largo plazo". Si el principio se puede establecer, incluso entre los ciudadanos con más alta formación es porque hay otros que no están entre los elegidos. Al contrario, las estadísticas laborales se compadecen mal y el empleo puede ser la fórmula que proponen agencias empresariales o gubernamentales para reciclar a la población que tiene poca o nula consistencia en la estructura laboral tecnologizada; esto ocurre si los contenidos están poco especializados, son generalistas, están mal pagados o son temporales. Son las disonancias de la maquinaria digital y las fórmulas big tech. No pueden ser contratados de analistas o diseñadores de programación por Google, Facebook, Microsoft, Apple, etc., pero quizá pueden estar en labores de limpieza o en los servicios de hostelería para mantener limpias y en funcionamiento las instalaciones de la economía digital.

Es hora de trasladar la idea clave: quiénes presiden la cuarta revolución industrial son por igual los logros, las disonancias y los problemas que crean (Schwab 2016). El punto de llegada dice que donde se constituye la sociedad big 
tech nace, emerge y se reproduce la sociedad auxiliar que vive para servir a la primera, está plagada de empleos poco especializados, temporales, mal pagados y alejados del talento tecnológico que es el ideal a seguir. La robotización y la automatización no resuelven los problemas, los presentan como inevitables con la esperanza de que los empleos "llegarán", como lo hicieron después de la 1a Revolución industrial.

Las disonancias no son las consecuencias no queridas o imprevistas, al contrario, forman parte de las actividades asociadas a este tipo de sociedades, realidades de la revolución tecnológica; son el otro rostro y la otra mirada. La era tecnológica no es el paraíso buscado sino la necesidad para ser y estar de la civilización socio técnica. La desigualdad no desaparece, la fragmentación tampoco y las nuevas turbulencias anuncian movimientos que ya se verá cómo enfrentarlos, a la afirmación socio técnica se la reconoce por el optimismo tecnológico y por las disonancias que crea. La situación deja una pregunta abierta para que la responda el Estado-Nación: ¿cómo ocuparse de estos hechos?

\section{EL PODER DE LA ESTRUCTURA TECNOLÓGICA}

Los Estados tienen competencia en el mercado de las respuestas. Pese al fervor democrático que desprende la era tecnológica por la pretendida participación de los usuarios en su puesta en escena, las fuerzas que más abusen de la cognosfera son las relacionadas con la digitalización. En la práctica, internet no depende de los discursos que se hacen sobre sus bondades o abusos sino sobre la estructura material que la mantiene. No hay nada utópico (Fergusson 2018: 489) en la propiedad de esa infraestructura y en los pactos que explican por qué las plataformas web producen tantos beneficios. El análisis de la estructura material de la propiedad expresa que los aspectos económicos, por ejemplo, de Facebook, Google, Amazon, etc., están a años luz de la ideología democrática o participativa. Se los ha comparado (Fergusson 2018: 417) con el sistema que proporciona herramientas de producción, pero concentran las recompensas en manos de una minoría. En Facebook, por ejemplo, "el usuario es el producto" y la comunidad de ciudadanos que promete sus discursos bienintencionados pero ideológicamente dirigidos, choca con una estructura material desigual. La plataforma cuenta con 15.724 empleados y casi 2.000 millones de usuarios, pero la participación en la compañía es otra cosa. El propio Zuckerberg posee apenas el 14\% de las acciones de la empresa. Los cofundadores, D. Moskovitz, E. Saverin y Ch. Hughes, menos del 13 por ciento, en conjunto. S. Parker y P. Thiel, tienen el 6,5\%, y otros dos inversores, Accel Partners, el fondo de riesgo de Silicón 
Valley y la empresa rusa Digital Sky Technologies, poseen el 10 y el 5,4\%. Sólo cinco entidades más-tres fondos de capital riesgo, Microsoft y Goldman Sachscuentan con un porcentaje superior al $1 \%$.

Las consecuencias sociales de la tendencia hacia los duopolios -Microsoft y Apple- o los cuasi monopolios-Facebook, Amazon y Google- son predecibles, pero paradójicos. El mundo está conectado de forma desigual. Seis de las ocho personas más ricas del mundo sostienen sus fortunas en las empresas de software, las telecomunicaciones, la venta online, las redes sociales, la información financiera o el software empresarial. Cada uno ha fundado algo parecido a un monopolio. La publicidad digital es el enorme negocio que controlan estos cuasi monopolios y el que crea la voz y la salida para negociar o comprar la competencia con otras ofertas empresariales.

Para las funciones básicas del Estado-Nación la era tecnológica causa heridas en la coraza que tenía preparada para administras, controlar y redistribuir los bienes colectivos. Hay tres detalles que deben tenerse en cuenta; el primero (Fergusson 2018: 479) es que la revolución de las tecnologías de la información es casi por completo un logro conseguido por Estados Unidos, si bien con la contribución de gentes llegada de todo el mundo en abierta peregrinación a la meca del saber: Silicón Valley, la Ruta 127, etc. El segundo es que las empresas tecnológicas estadounidenses más importantes poseen hoy en día una preponderancia extraordinaria. El tercero, es que este hecho se traduce en sumas enormes de dinero. Frente a esta transformación los Estados tienen, básicamente, dos opciones: capitular y regular, o excluir y competir. Los europeos parecen que eligieron la primera. La empresa de internet más importante que habita Europa es Spotify, con sede en Estocolmo. No hay, fuera de ésta, un buscador europeo, un vendedor online ni una red social europea. La opción de los Estados ha sido intentan controlar a los gigantes norteamericanos con regulaciones, acusaciones de situación de monopolio, leyes estrictas sobre la privacidad y la protección de datos. Los asiáticos, por el contrario, intentan con resultados más que estimables competir. Las viejas alianzas históricas tienen capacidad para ser transportados por los usos de la tecnología, hoy el muro asiático planta cara a las redes sociales y a los usos de la tecnología de origen estadounidense.

\section{EL LABERINTO DE LA CONEXIÓN Y LA DESIGUALDAD DE LA GEOGRAFÍA}

El Estado en la era tecnológica se sumerge en el análisis de la conectividad, tal y como por ejemplo la define P. Khanna (2016). En este nuevo laberinto, los argumentos sobre que son el clima y la cultura quienes condenan al fracaso a 
ciertas ciudades, o el argumento de que los pequeños países están atrapados y sometidos a las capacidades de los grandes, son ampliamente refutados. Gracias al transporte, las comunicaciones y las infraestructuras energéticas globales (carreteras, ferrocarriles, aeropuertos, oleoductos, y gaseoductos, redes eléctricas, cables de internet y demás), el futuro tiene una máxima para entenderlo: la conectividad.

El mapa del mundo es el mejor recordatorio de quienes somos. Si se escruta con mirada abierta permite ver la sucesión de países y fronteras alineadas por cuatro puntos cardinales: norte, sur, este y oeste. Si se cruza la mirada de los países según algunos de los ejes convencionales y se introducen especificaciones el mapa toma nuevas formas, como si estuviese dispuesto a hacerle hablar. Los mapas "hablan" y dan mucha información. Les invito, por ejemplo, a mirarlos desde algunos indicadores como: la esperanza de vida, renta per cápita, salud, educación o derechos ciudadanos. Enseguida, si se aplica la gama de colores, resaltan algunas diferencias porque descubre-si es que no se había hecho antesque hay zonas en el mundo donde la esperanza media de vida es superior a los 80 años, mientras otras llegan con dificultades a los cincuenta. Se alcanza enseguida una conclusión: no es baladí el país donde se nace. Me atrevo a ir más lejos y quisiera hacerles la viva recomendación, -sabiendo que no puede practicarse porque no se puede elegir-: si es posible "elija para nacer" un país del mundo desarrollado que combine renta per cápita, sanidad, educación, esperanza de vida y derechos ciudadanos.

Se nace por azar en uno u otro sitio, pero si el lugar donde vienes al mundo te lleva a ser el hijo de una familia que habita en los países ricos, la vida será más fácil, la esperanza de vida estará cerca o será superior a los ochenta años, tendrá la escolarización que dura al menos 14 o 16 años y, con frecuencia pueden ser hasta 20 años o más. Lo mismo con la ingesta de calorías, comerá varias veces al día y puede ocurrir que algunos problemas de salud surjan por la ingesta excesiva. Nacer en un país rico permite comer todos los días, aunque dependasen la peor de las situaciones- de agencias públicas o privadas: en las sociedades ricas alguien te ayuda o se encarga de ti, la intrincada red de organismos públicos $\mathrm{u}$ organizaciones privadas velan para que no te falten recursos básicos.

La salud es otro apartado, disfrutas desde de programas de vacunaciones que evitan contraer enfermedades que, a esa edad, pueden resultar letales o marcar el porvenir sanitario. Las vacunas, las visitas al pediatra, la alimentación y los cuidados que va a dispensarte tu familia y tu entorno social permiten, al menos en la inmensa mayoría de los casos, crecer alegre, confiado y con buena salud. Si 
tienes problemas con alguna lesión o enfermedad, la red médica asistencial cubre el espacio del país con hospitales y centros de atención primaria por si necesitas utilizarlos. La esperanza de vida depende de los cuidados de las familias, el intangible genético, las vacunas, la buena alimentación, el tratamiento médico y la asistencia ante cualquier problema o las preocupaciones que padezcas.

Los datos no se detienen aquí; descubre que la educación es una condición básica. Primero son las guarderías. Después a los dos, tres o cuatro años ingresa en la escuela primaria, después la secundaria para terminar en la Universidad o en las múltiples escuelas de aprendizaje profesional. Habrá pasado -depende del alcance de los estudios superiores- entre 16-20 años formándose como actividad preferente de su tiempo. El Estado, las familias y las instituciones especializadas habrán invertido más de 500.000 euros para que sea "ciudadano de bien". Ni que decir que en estas sociedades el acceso al empleo resulta, en términos generales fácil, el salario permite construirse un futuro, formar una familia, comprar vivienda, construir el itinerario biográfico vital de vida o cumplir algunos deseos. Vive en la sociedad que te respeta, te reconoce como ciudadano, puedes expresarte con libertad, leer lo que quieras, quejarte ante las autoridades cuando las cosas no te parecen que van bien o como tú desearías que fuesen, puedes formar parte de un sindicato o un partido político, aparecer o figurar como representante de tus vecinos o conciudadanos. Tienes derechos, dispones de recursos e instituciones que cuando las cosas van mal te permiten canalizar las protestas e incluso-por qué no- cambiar aquello que te parece injusto o no te gusta.

La mirada encuentra algunas respuestas: la situación descrita ocurre porque "tienes suerte", el azar te favorece, naces en la sociedad que ha creado el esquema de seguridad, planta en el suelo certidumbres y certezas y los ofrece porque formas parte de ella: familia, amigos, escuela, sanidad, universidad, compañía, asistencia, trabajo, salario, derechos individuales y colectivos, ciudadanía, en una palabra, futuro. Es posible por razones imposibles de comprender en ese juego que es el nacimiento: dónde vienes al mundo es muy importante, en qué país, en qué lugar de ese Estado, en qué familia, en qué entorno, cómo es la sociedad. No es lo mismo nacer en Dinamarca, Noruega, Suecia, Alemania, Holanda, Singapur, etc., que hacerlo en países que - aún hoy- no han conseguido poner las bases para recorrer el camino descrito. Nacer, por ejemplo, en algunos países africanos o en zonas asiáticas, supone tener casi la mitad de esperanza de vida, no escolarizarse o recibir escasa escolarización -frecuentemente no superior a cuatro años-, en la mayoría de los casos no albergar esperanzas de acudir a la universidad, tener una significativa mortalidad infantil porque la alimentación, 
los cuidados médicos o los programas sanitarios no están a disposición de toda la población. La estrategia vital produce supervivencia, el trabajo no es el bien asequible e inmediato y el salario-si se tiene la fortuna de tener empleo-es, con frecuencia escaso. La seguridad es el resultado, en muchos casos, de la fortuna.

El mapa del mundo "habla" de estas cosas, no tanto del valor de internet, o los éxitos de la tecnología de Silicón Valley. Cita y se cita con el crecimiento económico, el desarrollo social, con los buenos, los malos o los inexistentes sistemas de salud, comer varias veces al días, alimentarse correctamente, no morir en los primeros meses o años de vida por enfermedades vencidas en sociedades avanzadas, no poder asistir de forma regular a la escuela o asistir durante poco tiempo, tener que trabajar en condiciones difíciles, temer por la vida, carecer de derechos elementales o que la ciudadanía, en mucho casos, sea la imposible entelequia. Vivir al día e ignorar qué significa -de verdad-, la palabra futuro. No he decir que en estos lugares es vital la necesidad que exista un Estado que proteja, redistribuya y cree seguridad física.

Los mapas de conectividad conviven con realidades como las citadas, revelan las dinámicas geopolíticas entre las superpotencias, las ciudades-Estado, las compañías sin Estado y las comunidades virtuales de todo tipo en su competición por captar los recursos, los mercados y la atención de los consumidores. Estamos entrando-dice P. Kahnna (2017: 27-29)- en la era en la que las grandes ciudades tienen más importancia que los Estados y las cadenas de son una fuente de poder más importante que los ejércitos, cuyo principal objetivo será el de proteger las cadenas de suministros en lugar de las fronteras. La conectividad competitiva es la carrera armamentista del siglo XXI.

La conectividad es el mejor camino para vivir mejor y más seguros. La competencia por la conectividad es, por su propia naturaleza, menos violenta que los conflictos fronterizos transnacionales. La conectividad es la mejor forma de sacar partido a la geografía. El arco de la historia es largo, pero se curva hacia la conectividad. Es el nuevo metapatrón de nuestra era, no hay mejor inversión que la que se concreta en la conectividad. El gasto público en infraestructuras físicas o sociales a la larga ahorra costes y genera beneficios. Sólo -dice Khanna- hay una ley que nos acompaña desde que éramos cazadores- recolectores y que ha sobrevivido a todas las teorías rivales, ha trascendido imperios y naciones, y nos sirve como mejor guía para el futuro: la de la oferta y la demanda. Ésta es algo más que un principio del mercado para determinar el precio de los productos. La oferta y la demanda son fuerzas dinámicas en busca de equilibrio en todos los aspectos de la vida humana. Conforme nos aproximemos la conectividad 
infraestructural y digital universal, la oferta de todo tipo de productos puede satisfacer la demanda de cualquier cosa; prácticamente cualquier cosa o persona puede llegar a cualquier lugar, tanto en términos físicos como virtuales. Conforme se expande la globalización por cada rincón del planeta, las cadenas de suministros se extiendes, profundizan y fortalecen en tal medida que hemos de preguntarnos si representan en el mundo una fuerza organizativa más profunda que los propios Estados. Las cadenas de suministros son las redes mundiales originales que envuelven nuestro mundo como un ovillo. Son las tuberías y los cables del mundo, los caminos por los cuales se desplazan todas las personas y las cosas y están conectadas.

Para comprender el mundo actual -así lo expresa P. Khanna- debe lucharse con las fuerzas acumuladas más allá de la soberanía del siglo XVII, tales como la Ilustración, el imperialismo del siglo XIX, el capitalismo del XX y la tecnología del XXI. Un mundo joven, urbano, móvil y saturado de tecnología se explica mejor mediante los conceptos de incertidumbre, gravedad, e influencia más que con la lógica secular de la anarquía, la soberanía, la territorialidad, el nacionalismo y la supremacía militar. Una de las ideas es que la propia naturaleza del cambio cambia el cambio. Hoy en día estamos viviendo algo semejante, un cambio del cambio, es decir, no una mera transformación en la estructura de una superpotencia a múltiples potencias similares, sino más bien una transición mucho más profunda de un orden basado en los Estados a un sistema de actores múltiples. El antiguo mundo de los imperios inconexos cedió el paso al turbulento mundo medieval, que más tarde fue sustituido por el orden moderno de los Estados soberanos y, en la actualidad, por la transición hacia una completa civilización de redes globales. El cambio estructural acontece cada pocas décadas y los sistemas cambian poco cada siglo. El cambio estructural torna complicado el mundo; el cambio sistémico lo vuelve complejo. La conectividad es la principal causa de esta complejidad. Sin embargo, la conectividad consiste en que el cambio que brota desde el interior del sistema acaba transformando el propio sistema. Los conflictos del futuro no están relacionados con el establecimiento de nuevas fronteras, sino con el control de las conexiones. Probablemente nunca tendremos un libre mercado de carácter global, sino más bien un mundo en el que la economía mundial en expansión se convierta en un campo de batalla estratégico. De hecho, las economías se abren, pero no necesariamente conforme a las mismas reglas. Con todo, está surgiendo un consenso que respalda a estas fricciones sensatas, aunque también interesadas, que generan ventajas para el propio país y preservan las bases locales de la industria y del empleo, aun cuando no optimicen a la perfección su rentabilidad. 


\section{CUESTIONES DE POLÍTICA LOCAL}

Las tensiones que regula el Estado-Nación no habla sólo de cómo las transformaciones estructurales obligan a pensarlo sino cómo ocurren movimientos de naturaleza política que se mueven por redes micro, aunque el impacto puede ser macro. Uno muy relevante procede de las experiencias que aportan, por citar los más significativos, los casos de Escocia, Quebec, Cataluña o País Vasco. Fijándome en dos de los cuatro casos; del análisis del fenómeno británico y la experiencia canadiense, se extraen algunas conclusiones. Quebec dijo en dos consultas (en 1980, con el 40,5\% de los ciudadanos a favor de la independencia de Canadá y en 1995, con el 49,6\%) lo siguiente: i) las sociedades pueden preguntar los modos de vinculación con otras entidades políticas -en su caso Canadá-; ii) los resultados vinculan a las partes y iii) el bienestar, la democracia y la participación son los intangibles de la elección. El caso de Escocia con Reino Unido sigue derroteros similares: i) pacto, ii) decisión y iii) bienestar. En ambos casos el resultado es que la afirmación de la identidad nacional encuentra el punto de llegada en la afirmación del bienestar material como la expresión del objetivo fundamental de la nación, de forma que éste y la calidad de vida se transformen en el dosel sagrado de las metas nacionalistas.

Desde mi perspectiva, las dificultades proceden de la debilidad de dos dimensiones básicas: las funciones pragmática y simbólica. Al Estado se le cuestiona por la incapacidad para asegurar la integración práctica de la sociedad. La crítica procede de los agentes políticos y sociales que evalúan las disfunciones y la incapacidad para gestionar la complejidad de lo social en estos contextos. $\mathrm{Si}$ se analiza la trayectoria histórica de los últimos siglos, hay que coincidir con que la travesía histórica dice que es la que es.

Hay otras miradas que delatan el estado de la cuestión, citar el Estado-Nación significa incorporar fenómenos estructurales que interrogan los contenidos y el estado de la cuestión. Por ejemplo, el crecimiento del populismo en la vida política y la cultura. Puede preguntarse: ¿por qué citar este fenómeno? La respuesta trasmite la impresión que vislumbra el punto y final de la política tradicional, las formas de la democracia liberal y el tipo de Estado que hemos conocido (Mounk 2018) de modo que permite decir, al modo como se expresa T. Judt, (2010), "algo va mal". Hay una explicación, que desarrolla Mark Lilla (2004, 2017, 2018) en las obras, "Mente Naufragada", "Pensadores Temerarios" y "El Regreso Liberal”. La historia comienza con la descripción del Estado ordenado 
donde las personas saben cuál es su lugar en el mundo, viven en armonía, se someten al valor de la tradición y a los mandamientos de Dios.

Emergen ideas "extrañas" promovidas por intelectuales que perturban la armonía y la voluntad de mantener el orden se debilita en la cúspide social. La falsa conciencia desciende en el conjunto de la sociedad, mientras se encamina a la implosión. Los que conservan las viejas costumbres ven lo que ocurre. Como explica Lilla, "donde otros ven al río del tiempo fluir igual que siempre, el reaccionario ve las ruinas del paraíso pasar frente a él. Es un exiliado del tiempo". Vivir la vida moderna en cualquier lugar del mundo actual, sujetos al cambio social y tecnológico es como experimentar el equivalente psicológico de la revolución permanente. El reaccionario fabrica mitos históricos cuando culpa a la modernidad "tout court", cuya naturaleza es modernizarse a perpetuidad. La inquietud frente al proceso se vive e interioriza como la agresión, por eso las ideas antimodernas atraen a los partidarios que comparten pocas cosas, salvo la sensación de traición histórica. Los "reaccionarios" descubren que la nostalgia (Boym 2015), en ocasiones, pueden ser la base de la motivación política más poderosa que la esperanza.

En el epílogo a "Pensadores Temerarios" (Lilla 2017: 182), titulado: la seducción de Siracusa, advierte de un hecho, "es difícil -explica Lilla- encontrar un siglo en la historia europea mejor diseñados que el último para excitar las pasiones del pensamiento y llevarlo al desastre político (....). Por mucho que se reflexione sobre estos movimientos, todavía estamos lejos de entender el conflicto que los intelectuales europeos mantuvieron consigo mismos y las estratagemas que utilizaron para mantener sus ilusiones". Más adelante apunta a un hecho sugerente, "la era de las grandes ideologías dominantes quizá haya acabado, pero mientras hombres y mujeres piensen políticamente, el riesgo de sucumbir a la seducción de la idea permanecerá vivo. Y también seguirá vivo el riesgo de dejar que la pasión nos ciegue e imponga su potencial despótico y de abdicar de nuestra verdadera responsabilidad, que es la de dominar el tirano que llevamos dentro"

El desmoronamiento de los credos que sostienen la expansión del concepto liberal de Estado-Nación puede seguir caminos diversos: los que se abren hacia la nostalgia, los que perciben que las cosas no son como eran, el tradicionalista (Bellah 1989) cree que si se ausculta el pasado puede encontrarse algo mejor que en el presente, aunque lleve a olvidar que el tradicionalismo es la fe muerta de los vivos, cómo si cuando se parte de las virtudes de la nostalgia se pudiese reconstruir caminos míticos que, en realidad, nunca fueron andados o soñar con 
penetrar en los que nunca se experimentan. La interiorización de la derrota puede volver nostálgico al sujeto contemporáneo, vivir la traición a la vida y a sus ideales para construirse refugios donde encontrarse con otros que están en la misma longitud de onda, sobre todo si sospecha que la cercanía al ideal del nosotros le proporciona el sentido de pertenecer al nosotros construido desde la nostalgia y la victimización de lo que les ocurre. Los grupos sociales desarrollan espasmos de miedo ante la falta de seguridad, encuentren el origen en nuevas coyunturas: económica, laboral, religiosa, identitaria, política o cultural.

Reconocerse en narrativas nostálgicas "clarifica" dos cuestiones: i) quién es la víctima; y ii) quién el culpable, hacia donde mirar o cómo buscar para colocar la etiqueta de culpable o inductor de la situación "desmoronada" que padece. Los hechos enlazan con las dudas que exponía hace décadas E. Shils (1982) cuando introdujo los conceptos de centro y periferia. Empleando esta conceptualización los procesos afectan a la definición de que es y dónde está el centro que crean las sociedades. Éste- el centro- pertenece a la esfera de los valores y es la metáfora que describe qué es lo importante en el sistema de valores de una sociedad y los elementos que son críticos. Es, en la definición de E. Shils, "el sistema de valores central'. El centro representa, en palabras de Liah Greenfeld (2016: 148), el código genético social.

La situación se descubre, por ejemplo, en los resultados del Brexit y en las coyunturas políticas de algunos países europeos. Las enseñanzas se pueden rastrear en la dimensión estructural del votante pro-Brexit, la geografía electoral del voto y en los discursos que mueven la toma de posición. Los hechos permiten ver lo que hay que tener en cuenta para evaluar de "qué se habla" o "por qué se quejan" los ciudadanos parapetados detrás del valor que concede al EstadoNación.

El discurso dice lo siguiente: la Europa comunitaria, tal y como se conoce, es responsable de los males sobrevenidos a Gran Bretaña. Se produce la doble vinculación que explica quién es la víctima y quién el culpable. Las víctimas se quejan, demuestran insatisfacción y colocan sobre las espaldas de otros las razones de los problemas. En política social, por ejemplo, es el que se queda con los subsidios sin tener -o eso creen- derecho a ellos, el que hace uso de la sanidad pública, el que recurre a los servicios públicos, etc. Dicho de otra manera, el Otro es el responsable de lo que ocurre. Localizados los responsables: Europa, algunas elites políticas, los partidos de izquierda, etc, el discurso dice que la política comunitaria manda, ordena e impide a los británicos ser. El resultado es inquietante: los sectores jóvenes son defensores de la UE, las generaciones 
mayores deciden que lo mejor es darse de baja del club UE y caminar "solos por el mundo".

Otro dato es la localización geográfica del voto. Las grandes ciudades- con Londres a la cabeza-, son partidarias de seguir en la UE, las ciudades medias y la campiña inglesa son del Brexit. No sé si puede catalogarse la división geográfica como un recurso de los procesos de renacionalización y rupturas -al menos aparentes- con las fuentes europeístas, pero los datos indican que las periferias urbanas y las partes dañadas por los procesos de desindustrialización se inclinan por ver a Europa como culpable de los males y causantes del malestar; sean la amenaza a la identidad británica o el desmoronamiento de la industria tradicional que permitió construir el futuro. Las "periferias" de fuerte identidad nacional- Irlanda del Norte y Escocia-, son los caladeros del voto Remain, junto como hemos dicho- las grandes ciudades y los sectores más jóvenes de la población. La cuestión geográfica no es el asunto baladí, todo lo contrario. El tamaño de la ciudad, la vida rural o ser ciudadano de grandes ciudades no son tres asuntos menores. Los datos demuestran que las grandes ciudades, concretamente Londres, el $60 \%$ de la población vota a favor de la permanencia en la UE.

El libro de E. Moretti (2012), "La Nueva Geografía del Trabajo" plantea algunos interrogantes; i) las personas con estudios universitarios son la mitad de la población total en las áreas metropolitanas ricas; ii) son cuatro veces menos en las áreas menos desarrolladas; iii) hay más concentración de talento, mano de obra cualificada bien formada en las áreas metropolitanas y con mayores niveles de renta; iv) los cambios que impulsan la tercera y cuarta revolución industrial acentúan esta división; V) quienes viven y trabajan en las ciudades industriales medias, tradicionales áreas de la industria manufacturera clásica, se ven atrapadas por las consecuencias de la cuarta revolución industrial y en muchos casos no tienen recursos para enfrentarse a lo que se les viene encima; vi) la desindustrialización no es la mejor compañera de viaje, como tampoco son la pérdida de puestos de trabajo, la desvalorización del patrimonio inmobiliario quiebra las comunidades y la cultura obrero industrial; vii) hay dificultades para insertar las nuevas generaciones $\mathrm{y}$, en muchas ocasiones, en estas áreas desindustrializadas se promueve la anomia y la ausencia de referentes culturales claros en la definición del futuro de la comunidad, antes industria, la cultura obrero industrial y la solidaridad de clase están en vías de extinción.

Los instrumentos empleados son las transferencias fiscales a zonas expuestas con objeto de ayudar a contrarrestar la desigualdad y combatir la pobreza. Las 
acciones tienen límites para transformar el tejido social y combatir la desigualdad. Una vez más, las transferencias fiscales y las políticas sociales son dos recursos para contrarrestar situaciones de dependencia, es difícil prever que éstos puedan ser factores de compensación para períodos de tiempo prolongados. La cronificación de las ayudas compensan algunas dificultades y tienen otros efectos difíciles de calcular cuando la sostenibilidad resulta dudosa. El resultado es la carencia de respuestas desde los entornos socio productivos. Las ayudas generalizadas promueven a corto plazo falsos momentos de prosperidad y a medio no ayudan al despegue que necesitan las áreas urbanas desindustrializadas.

En otros países europeos, los efectos reflejan similares tensiones. En Holanda, los comicios se entienden como la primera vuelta respecto al papel electoral del populismo de derechas en Europa. Los augures pronosticaron la posibilidad de que el gobierno holandés fuese ocupado por la fuerza política de G. Wilders extrema derecha-. Nada de eso ocurrió. Holanda vive con el panorama político fragmentado y secuelas de la crisis económica. No es inusual que cuatro partidos deban ponerse de acuerdo para formar gobierno, por infrecuente que parezca, que la izquierda tradicional- partido socialista-tengan una caída histórica no es desconocido, que los partidos que ascienden sean nuevos o en otros tiempos tuviesen una presencia residual: -ecologistas y D66 -liberales de izquierda-, que la alta participación (82\%) acompañe el cambio político tampoco resulta novedad.

Las elecciones introducen elementos sugerentes; i) la fragmentación política -no es nueva pero obliga a crear culturas de pacto-; ii) el incremento de la participación no favorece a las expresiones populistas de extrema derecha, de tal suerte que cuando se incrementa la participación, los partidos tradicionales ceden, la realidad política se fragmenta, pero a la vez reorienta el sentido del voto y los valores centrales que alimentan las ideas de bienestar, calidad de vida y confianza institucional son las ganadoras; iii) en general "ganan" los partidos que exponen mejor el sentido profundo de seguridad y la capacidad de gestionar las incertidumbres, se "huye" de propuestas extremas porque el riesgo que se está dispuesto a pagar por ellas es limitado.

Otro ejemplo es Francia. En abril del 2017 se celebra la primera vuelta de las elecciones electorales, en mayo se completa la elección presidencial y en junio se cierra el círculo con la elección de diputados a la Asamblea Nacional. Los cinco datos más llamativos son: i) el triunfo de E. Macron, antiguo ministro de economía del gobierno socialista de F. Hollande, hombre sin partido político, fuera de los canales tradicionales de las dos grandes fuerzas de la derecha y la 
izquierda: republicanos y socialistas. De hecho construye en un año un partido singular para sostener su candidatura: La República en marcha; ii) el programa es híbrido, toma elementos del liberalismo y del socialismo liberal para componer un puzle con respuestas políticas que no siguen, o no lo hacen al pie de la letra, la definición que habían hecho las grandes corrientes políticas francesas; iii) los dos partidos bastiones de la $\mathrm{V}$ República, demuestran que si la derecha tradicional está viviendo la peor crisis de los últimos cincuenta años, el partido socialista está en un proceso de implosión que puede llevarle a la irrelevancia; iv) el crecimiento de la extrema derecha del Frente Nacional está contenida, limitada a vaivenes con momentos coyunturales donde crece y parece que amenaza el orden republicano francés, para pasar a continuación a situaciones normalizadas; 5) Europa sigue estando en la agenda política francesa como un elemento clave de su identidad política.

La agenda de E. Macron atiende a tres problemas de cuyos resultados dependerá el éxito del mandato; i) políticas de seguridad social que, por una parte protegen a los más débiles y, por otra, permite la flexibilidad del mercado laboral y el funcionamiento de una economía dinámica.; ii) el fomento del sistema industrial que favorezca la innovación tecnológicas e impulse el emprendimiento, de modo que los "nuevos" puedan competir con las empresas establecidas en cualesquiera de los sectores económicos y; iii) mantener los compromiso con la apertura económica, la integración europea y la globalización.

Salir de compras políticas por Europa enseña algunas cosas; 1) pese a la interconexión entre unos países y otros, la singularidad de los problemas marca, de manera significativa, las respuestas que se ofrecen; 2) la edad, el relevo generacional se vive en algunos casos -Gran Bretaña, especialmente- como brecha generacional con los mayores. La movilización de los jóvenes, cuando se produce, provoca cambios en el sistema político, en la orientación del voto y en las políticas públicas; 3) el carácter híbrido de la política. El eje derechaizquierda no ha desaparecido, pero se ha atemperado y los éxitos políticos dependen, cada vez, más de la capacidad de los líderes para tomar préstamos de las dos grandes tradiciones políticas -liberalismo y socialismo-. Los casos de Francia y Holanda demuestran que el hibridismo en política viene para quedarse; 4) el éxito político, por precario que sea, se encomienda a la protección de las políticas ligadas al Estado de bienestar, la calidad de vida y la confianza institucional. Nadie triunfa negando las esencias de la tradición política europea que ha envuelto al menos a las dos últimas generaciones de ciudadanos continentales. Incluso la extrema derecha practica un discurso abiertamente social y de aproximación a los sectores sociales desfavorecidos; 5) el éxito político 
es "hijo" de la creación de seguridad y de la capacidad creada para gestionar incertidumbres; 6) la desigualdad y la ausencia de definición de por dónde debe ir el futuro son problemas de los que hay que ocuparse. El convencimiento popular dice que con los recursos que el Estado administra es posible crear políticas sociales públicas para atender las situaciones precarias y a los sectores sociales desfavorecidas; 7) los mecanismos de la democracia no están para gestar el ideario o la interpretación del presente alrededor de la figura del chivo expiatorio -sean los cupos de inmigración, la seguridad pública, el terrorismo, etc.-. El mensaje es: la democracia puede y debe enfrentar y resolver ese tipo de problemas. Fuera la vida es experimental y más difícil.

La extrema derecha europea emerge con rostros diferentes, pero con miradas afines y características estructurales que gestionan las debilidades de los supuestos sobre los que se erigió el Estado del Bienestar. La práctica política es nacionalista y social, nostálgica y tradicional y selectiva en la memoria. No rechaza la democracia y rebaja las pretensiones del paradigma democrático, culpa a las elites de no cumplir con las expectativas que crean y les obligan a seguir caminos prediseñados, rebajan las libertades fundamentales, expulsa de los frutos de los logros económicos a quienes creen que no son oriundos o nacionales del país. Es el ejercicio paradójico, pero eficaz, de los déficits y de la quiebra del paradigma gestado en la edad de oro del bienestar europeo y de la firma del contrato que permitió hacer posible la paz social que vive Europa. En todos los casos está presente la discusión sobre el Estado.

\section{MIRAR HACIA ASIA}

Otras voces, y otras maneras de vivir ganan adeptos entre los que contemplan el edificio de la solvencia europea. El Sureste Asiático es una de las posibilidades de la mirada. Las razones las resume bien U. Pipitone (2003: 325); varias economías de la región -dice el autor- han dado el salto más allá de las trampas del subdesarrollo, lo que deja entrever la puesta en marcha de una corriente ascendente secular, similar a la occidental, de productividad y bienestar social. El reforzamiento de conexiones tecnológicas, comerciales y financieras a escala regional tienden a crear intereses comunes capaces de evolucionar hacia nuevas formas de cooperación y posible, pero aún lejana, institucionalización. Asia Oriental es uno de los tres protagonistas económicos de mundo y es difícil imaginar (a menos de impredecibles turbulencias políticas catastróficas) que la situación sea revertida en el futuro. Como América del Norte y Europa, Asia oriental está entrando a un nuevo ciclo de la propia historia en que las 
enseñanzas del pasado no serán suficientes para alumbrar el camino hacia el futuro.

¿Hay un modelo general que conecte unos países y otros? Es excesivo concluir que exista tal cosa, hay correspondencias a tener en cuenta (Pipitone 2003: 328329). En primer lugar, los países experimentan la primera fase de sustitución de importaciones que rápidamente transita a estrategias exportadoras de manufacturas. Inicialmente son productos de baja intensidad de capital y gran demanda mundial para ir hacia productos tecnológicamente sofisticados y con una creciente dotación de capital por trabajador. Es destacada la capacidad pública para fijar escenarios de comportamiento o colectivo. Los elevados niveles de ahorro interno, complementados con la disponibilidad de ahorro regional terminan por alimentar la red productiva en la que cada nuevo país fortalece la capacidad de todos los demás. Las reformas agrarias contribuyen a la generación de ahorros, a la absorción de mano de obra excedente, sino también a la formación de mercados locales con nuevos encadenamientos productivos. En el ciclo de crecimiento acelerado y transformación estructural de las economías asiáticas, la forma política dominante es el régimen autoritario que supo proporcionar tres inputs: creación de administraciones públicas con un alto grado de eficacia administrativa, estrecha vinculación entre alta burocracia y las empresas privadas y el relativo aislamiento del quehacer político de las presiones sociales circundantes.

Si tomo de ejemplo a Singapur, puede coincidirse que es uno de los milagros de los últimos setenta años. Los habitantes disfrutan de altos niveles de vida, buenas escuelas, hospitales y el Estado sólo invierte el 17\% del PIB en gastos sociales. Singapur es más autoritario, más intervencionista, más jerárquico que los países occidentales y más elitista. Dicen J. Micklethwait y A. Wooldridge (2015: 129) que "Singapur es un pequeño Estado vigilante nocturno que proporciona a la gente las oportunidades que necesitan para levantarse y luego los deja resolver su propio bienestar. Siempre que no cuestionen el orden social, los ciudadanos de Singapur tienen un enorme control sobre cómo gestionar su salud y solucionar su vejez".

El modelo de modernización desafía dos principios básicos del Estado occidental: i) el Gobierno tiene que ser democrático y; ii) generoso. K. Mahbubani (2002: 191), decía, "cuando Singapur obtuvo su independencia en 1965, sus líderes se sintieron preocupados antes que dichosos a la idea de que una diminuta ciudadestado insular de 2 millones de habitantes y carente de territorio interior pudiera sobrevivir en la que era entonces una región difícil y agitada semejaba una 
quimera inasequible. Así, lo notable no es que este país haya desafiado todas las circunstancias, sino que se haya convertido en una de las naciones más exitosas del mundo". La modernización no regula la relación entre el establecimiento de la democracia liberal y el crecimiento económico, sino que instaura la "democracia autoritaria" basada en fuertes liderazgos. Hay autores como Stanley Tambiah (1992) y Tu Wei-ming (1996) que estudian la aportación de la doctrina confuciana a la modernidad asiática y rechazan la noción del individuo cerrado en sí mismo que se centra en el papel de los colectivos, la cohesión y las conexiones sociales.

El éxito económico dice que el país crece a un índice anual superior al 7\% desde la independencia en 1965, lo que deriva que el ingreso anual per cápita es el noveno del mundo. Como cuenta K. Mahbubani (2002:192) las prescripciones políticas que lo logran son simples: "sostenimiento de una economía libre y abierta, eliminación de todos los subsidios, apertura a la inversión extranjera y busca de superávit presupuestario. El trabajo arduo, el ahorro y las virtudes implicadas por el incremento de la productividad laboral fueron permanentemente alentados". Las políticas no se ajustan al pie de la letra ni al paradigma capitalista ni al socialista. Les anima el pragmatismo, la apertura a la experimentación y la innovación.

El $90 \%$ de la población habita viviendas públicas que cubren el sexto del territorio. El sistema de salud está cofinanciado. La educación no es totalmente gratuita, pero el $90 \%$ de los escolares concluye al menos 10 años de estudio, $20 \%$ termina estudios superiores, $40 \%$ realiza estudios politécnicos. La imagen que emplean J. Micklethwait y A. Wooldrigge $(2015,130)$ es descriptiva, "es una especie de Mary Poppins; no sólo es una niñera maravillosa sino también muy mandona y quizá un poco siniestra". "Nosotros decimos lo que es correcto", dijo Lee Kuan Yew (2015) en una ocasión, "no importa lo que la gente piense". La descripción introduce otro axioma básico; la convicción de que una democracia real, sin controles desde el poder, no funciona en los países en desarrollo, claramente va más allá de su propio interés. También dejó escrito: "lo que un país necesita desarrollar es la disciplina más que la democracia".

El buen gobierno se basa en la élite bien educada que gestiona el país. La praxis del Estado está acorde con este principio. La tradición del mandarinato atraviesa la definición del buen gobierno y la selección de las personas con más talento para el gobierno. Detecta precozmente jóvenes con talento atrayéndolos con becas, y luego invierte en su educación. Quienes superan la selección son recompensados con salarios elevados, mientras que los que no superan las 
pruebas quedan un tanto olvidados. En un sistema con estas características, la meritocracia es la clave de la organización del sistema político. Las pruebas, el examen, son omnipresentes. Las elites están al día sobre las nuevas ideas de gestión y dispuesta a importar los métodos de éxito del sector privado al público. No atrae, en cambio, el Estado del Bienestar al estilo occidental. No se identifican con la política de subsidios, están convencidos que la democracia es parte del problema de Occidente. "En una democracia popular, para ganar votos hay que dar más. Y para vencer al oponente en las próximas elecciones, hay que prometer dar aún más. Es un proceso indeterminado de subastas cuyo coste es que la deuda la pague la siguiente generación" (Micklethwait y Wooldrigge 2015: 134).

El mensaje es sugerente por dos razones. A los nuevos estados de Asia les falta el modelo que canalice los deseos alimentados por el resurgimiento del nacionalismo y la demografía. El Estado del Bienestar no se basa en la asistencia social como en Occidente sino en seguros sociales como en el caso de Singapur. La segunda razón es la crisis del modelo occidental de democracia y el capitalismo de libre mercado. Se comparten tres convicciones: i) la democracia occidental no es eficaz; ii) el capitalismo como la sociedad necesitan ser dirigidos y; iii) encontrar las buenas formas de gobierno es la clave del éxito y la supervivencia del régimen (Micklethwait y Wooldrigge 2015: 138).

El problema de fondo lo recoge K. Mahbubani (2002: 26), "hay un increíble desempeño económico de las sociedades del este de Asia en los últimos decenios. Hoy las mentes asiáticas ya no se creen condenadas a imitar; saben que pueden hallar sus propias soluciones. Han visto que los asiáticos ya no juzgan que las sociedades occidentales sean el modelo a seguir. Han comenzado a creer que pueden intentar algo diferente. La tercera razón es que la elevación del nivel de vida de un creciente número de asiáticos por encima del grado de subsistencia les ha conferido la necesaria libertad económica para pensar, reflexionar y redescubrir su herencia cultura. Ello ha dado origen a una conciencia cada vez más aguda de que, como los occidentales, también sus sociedades poseen un rico legado social, cultural y filosófico que pueden revitalizar en beneficio de su evolución".

El modelo es un desafío por una razón: funciona. El pragmatismo socio estatal indica que otras formas de organización son posibles y pueden funcionar. En la búsqueda que emprende el mundo occidental, Asia y el paradigma, en concreto de Singapur, puede ser para algunos un referente que pueda sostener tasas de crecimiento económico, calidad de vida y cohesión social. Estos bienes no tienen por qué buscarse -exclusivamente- en los anales de la democracia liberal europea 
o norteamericana, como si pudiese ser el instrumento que se emplea a gusto de cada cual, al margen de la longevidad y la enorme carga cultural que arrastra consigo. La fascinación por la crisis camina en paralelo con la mirada sobre Oriente, aunque puede pensarse que son obras de restauración para el viejo edificio occidental y siendo así mejor nos quedamos como estamos, la alternativa existe y no está o no parece encontrarse sólo en Occidente.

\section{RELEER LOS SENTIDOS DE ESTADO-NACIÓN}

Como ponen de manifiesto las teorías existentes, la globalización representa la puesta en escena de multiplicidad de vínculos entre los Estados, las sociedades y la puesta en cuestión de los supuestos desde los que se había pensado, organizado y vivido la sociedad moderna como sociedad nacional con unidad territorial. Los sucesos asociados a las transformaciones estructurales permiten que la asociación entre Estado nacional y sociedad nacional esté en entredicho ¿Por qué hago esa afirmación? La sociedad que emerge del proceso global es policéntrica, se mueve en el horizonte en el que el capital, la cultura, la tecnología y la política se mezclan más allá del poder de organización de los Estados nacionales, sin que signifique que hayan desaparecido y pierdan fuerza o virtualidad. Se puede opinar- como hace Z. Bauman (2001)- que no se espera de los nuevos Estados, ni de los longevos, que realicen la mayoría de las funciones que antes se consideraban la razón de ser de las burocracias estatales nacionales. Los Estados nacionales se convierten en ejecutores y plenipotenciarios de fuerzas sobre las cuales no tienen la menor esperanza de ejercer algún control, son Estados débiles que necesitan el nuevo orden mundial para sustentarse y reproducirse. Es fácil indica Z. Bauman- reducir un Estado débil a la función de una estación de policía local, capaz de asegurar el mínimo de orden necesario para los negocios, pero sin despertar temores de que pueda limitar la libertad de movimientos del capital.

Como pregunta M. Mann (2000), ¿ha terminado la globalización con el imparable ascenso del Estado nacional? o es más acertada la opinión de J. Gray (2001) de que los Estados-nación deben actuar en el mundo en el que todas las opciones son inciertas. Los gobiernos nacionales están inmersos en entornos de riesgo e incertidumbre radical y es la incertidumbre la que limita el poder de los Estados soberanos. La incertidumbre de J. Gray responde a la pregunta de M. Mann: ¿son sus redes globales "puras", en el sentido de ser singularmente universales, o están coadyuvando a constituirlas otros principios más particularistas de organización social? La respuesta tiene solvencia empírica, la 
economía puede ser global, pero es posible gracias a la existencia de redes de interacción nacionales e internacionales.

Para M. Mann el Estado-Nación proporciona parte de la estructura de las redes capitalistas globales. Las mercancías existen mezcladas con la ciudadanía. Si la economía es global resulta de la combinación de elementos transnacionales, internacionales y nacionales. Las sociedades humanas las componen redes de interacción múltiples, solapadas y entrecruzadas. Las formas de interacción penetran el globo de forma plural, cambiante y desigual. Caben plantearse dudas respecto a la tesis de la crisis del Estado-Nación. Es sugerente la singularidad histórica de los Estados-Nación para comprender las dificultades que presenta "su" superación. Como indica M. Billig (2014) uno puede tomar cocina china mañana y turca al día siguiente; puede incluso vestirse al estilo chino o turco, pero ser chino o turco no son opciones posibles para este tipo de actitudes.

El problema es encontrar las formas de organización política que hacen justicia a las relaciones globales. La complejidad de la globalización y los límites sociales y económicos señalan las dificultades para construir modelos capaces de organizar fidelidades múltiples. No cabe resumirlo acudiendo a modelos de convivencia racionalizando el reparto del poder político o recurriendo a la habilidad de las instituciones para vincularse a niveles subnacionales de gobierno -regional o local-, por ejemplo, mediante la deliberada extensión del principio de subsidiaridad, según el cual las instituciones superiores sólo se encargan de las decisiones que los niveles inferiores de gobierno, incluido el Estado- nación, no pueden asumir con efectividad. Como ejemplifica Geertz (2002), en "el mundo astillado debemos estar con las astillas".

Con perspicacia pregunta D. Rodrik (2012: 219) lo siguiente: “¿cómo gestionamos la tensión entre una democracia nacional y los mercados globales? Tenemos-dice- tres opciones. Podemos limitar la democracia con el propósito de minimizar los costes de transacción internacionales, sin tener en cuenta los trastornos económicos y sociales que la economía global produce en ocasiones. Podemos limitar la globalización, con la esperanza de reforzar la legitimidad democrática en el país concreto. O podemos globalizar la democracia a costa de la soberanía nacional. Este menú capta el trilema político fundamental de la economía mundial: no podemos tener hiperglobalización, democracia y autodeterminación nacional todo a la vez. Podemos tener, como mucho, dos de las tres. Si queremos hiperglobalización y democracia tenemos que renunciar a la nación. Si hemos de mantener la nación Estado y también queremos 
hiperglobalización, tendremos que olvidarnos de la democracia. Y si queremos combinar democracia con nación Estado, adiós a una globalización profunda".

La inteligente advertencia de D. Rodrik (2012) pone en el esquema analítico muchos interrogantes, pero la propuesta se olvida que se quiere todo a la vez y además no pagar por ello costes inasumibles. En todos estos casos, la interdependencia promueve conexiones múltiples e intrincadas, lo que no genera es claridad en las relaciones y sí fórmulas difíciles de digerir. La globalización requiere la desaparición o la manipulación de las fronteras, algo a lo que se oponen los Estado y a lo que la democracia pone reparos porque las posibilidades de regular y controlar las políticas nacionales son, en estos casos, más deseo que realidad.

Quizá estemos ante el tiempo que niega las grandes ideas y afirma el abandono de otras nociones sintetizadoras. La perspectiva requiere aceptar lo que propone, por ejemplo, Ch. Taylor $(1978,1993)$ cuando hace de la diversidad y la pluralidad los modos de pertenencia a nuevas formas de estar. En el mundo de lealtades múltiples (Walzer 1996), las identidades son diversas y variadas, la interdependencia aúna valores individualistas con otros comunitarios y colectivos, eso son de esperar y deben ser bien recibidas gran variedad de reglas institucionales. Cada una tendrá su utilidad y causará problemas concretos: ninguna es permanente. Negociar las diferencias es el trabajo que no garantiza el éxito. Como dice C. Geertz, (2002) ¿qué lugar ocupan en este mundo hecho añicos los grandes conceptos, integradores y totalizadores, que solíamos usar cuando organizábamos nuestras ideas sobre política mundial y, en particular, sobre las similitudes y las diferencias entre pueblos, sociedades, estados y culturas: conceptos como tradición, identidad, religión, ideología, valores, nación, cultura, sociedad, estado o pueblo? Pero, sean unas o sean otras, algunas nociones generales, nuevas o reinventadas, deben construirse si es que queremos captar el fulgor de la nueva heterogeneidad y decir algo útil sobre sus formas y su futuro.

\section{¿RECUSAR EL ESTADO? ALGUNAS CONCLUSIONES ABIERTAS}

El estado de la cuestión anuncia un mundo difuso, débil en los lazos interiores, global y dividido, interconectado y fragmentado. No hay oposición entre la conciencia cosmopolita y la particular, sino que ambas se refuerzan. Detrás de la preocupación está presente la metáfora de la torre de Babel. La catástrofe del retrato bíblico narra la escena originaria de confusión e incertidumbre provocadas por el descubrimiento de que existen múltiples narrativas para 
comprender el origen del mundo. La confusión de lenguas se refiere a la llegada de la diversidad y a cómo entenderse desde las diferencias. Bajo las formas de este enigma emerge la articulación del pluralismo y la pregunta: ¿desde qué ideas y/o principios pueden construirse los mínimos comunes que hacen posible la convivencia en la diferencia y la articulación de la sociedad? Responder es encarar a la relevancia estratégica y funcional de las maquinarias burocráticas de los Estados y plantearse las reivindicaciones de los discursos nacionalistas por si estuvieran reproduciendo el mismo modelo obsoleto del que acusan a los Estados Nación tradicionales.

La política no sale indemne de estos procesos porque debe pensar la identidad de sociedades complejas y plurales definidas desde un grado elevado de aceleración y desde el poder de la tecnología y la globalización impulsa la disolución y las necesidades de la pertenencia y la vinculación, pero la pregunta es: ¿cómo se vinculan personas, mercancías e intereses en la geografía mundial presidida por la torre de Babel y la confusión de lenguas? Si se enciende el círculo de la interdependencia puede pensarse el discurso de la Nación y el Estado. La interdependencia lee los particularismos desde la quiebra del discurso de la única razón de estado, lo que plantea las dificultades es hacerlo con la caja de herramientas del legado decimonónico. La paradoja es que quizá hay que prescindir de él pero, a la vez, sin él no se sabe bien cómo actuar, como si se descubriese que el cuadro de necesidades se mueve con un ritmo y la caja de herramientas no tiene capacidad para hacerlo, como si estuviese huérfana de "tuercas y tornillos" para plantear de otro modo la reconversión del Estado y la Nación.

M. Walzer (1996) ve que cuando se olvida la sutil y delicada frontera que componen las lealtades sociales se olvida el hecho de que todos los individuos están divididos e incluso se desarrollan bajo la diferencia. Si la experiencia es pacífica aumenta el poder del sujeto que puede maniobrar a lo largo de alternativas $\sin$ quedarse encerrado en la defensa de una sola. Si las identidades son diversas y la interdependencia permite aunar valores individuales con comunitarios y colectivos, son de esperar gran variedad de reglas institucionales. Cada una tendrá sus utilidades, algunas causan problemas y ninguna es permanente. Negociar las diferencias es un trabajo arduo, doloroso y, en ningún caso, está garantizado el éxito. Por otra parte, a medida que se expanden las interconexiones surgen límites y configuraciones sociales y políticas, mientras otras se contraen o desaparecen. Cuando ocurre esto, las identidades no pierden la oportunidad de alterar los vínculos e incluso los contenidos de los significados internos. 
En la panoplia de cambios cabe preguntarse: ¿cómo pensar nuevos espacios políticos? ¿cómo repensar el Estado?, ¿cómo se desenvuelve la nación? La insistencia en la constelación nacional, en el valor del Estado o la incertidumbre encierra más el diagnóstico de lo que pasa que propuesta alguna sobre lo que puede ocurrir. Otro tanto ocurre con la organización política y simbólica del poder; la ilusión soberanista pugna con nuevos poderes políticos. Las reglas de juego apuntan al principio de organización cuyo rasgo es la interdependencia. En el suelo se cruzan competencias que proceden de áreas políticas tradicionales, espacios políticos descentralizados y las de aquellos otros que permiten que emerja el proceso de globalización. En el juego cambian las reglas, el poder político está fragmentado y repartido en el juego de fuerzas ilimitadas, sin un centro claro.

La consecuencia es que se asiste no a la defunción del Estado sino a la emergencia de nuevas formas de organización política que emergen desde él y que sin negarle se definen desde la interdependencia y el juego de las diversas competencias donde nadie tiene respuestas definitivas y los resultados se ven si se juega.

La conclusión es que emerge la estatalidad como la forma de organización del poder político que rechaza visiones tradicionales, afirma el poder de la política y responden al marco de relaciones donde están las redes y el juego, pero no desaparecen el centro ni la periferia. Detrás está la articulación de las sociedades plurales y las preguntas consiguientes. No creo en las perspectivas que hacen bandera de la homogeneidad, la identidad compartida, los derechos inalienables o el patriotismo constitucional, sino con aquellas perspectivas que confían en los mínimos que la población comparte. Para ver esto es preferible acudir a la cotidianeidad de la vida social donde los individuos se encuentran en situaciones dispares, hablan, discuten, negocian y comparten los principios creados en las redes y en las relaciones sociales que allá se formalizan. De esta manera, respuestas tenues aseguran la interdependencia.

M. Ignatieff (2018: 13) lo expresa bien en el texto sobre Virtudes cotidianas. "vivimos en tiempos de fractura. Los movimientos nacionalistas están poniendo a prueba la unidad de los estados. Los partidos consolidados están perdiendo su dominio sobre el centro y los ciudadanos están desplazándose hacia los extremos, mientras que la parcialidad política es más intensa que nunca. Nuestra convicción tranquila de que la historia nos estaba conduciendo hacia un futuro estable compuesto por democracias liberales se ha desvanecido, al igual que desapareció durante la crisis económica global de 2008 una creencia similar en la 
estabilidad a largo plazo del capitalismo". En este contexto y bajo estas características, la pregunta es pertinente: ¿dónde se puede encontrar orden y estabilidad? "Debemos dejar de lado-dice- la visión general y fijarnos en los pequeños detalles, pasar del amplio mundo de la política, los mercados y el sistema internacional al mundo más pequeño y más íntimo de la familia, el barrio y la esquina. Es ahí donde nos encontramos con el ámbito de las virtudes cotidianas-la tolerancia, la resiliencia, la confianza y el perdón- del que depende el sistema operativo moral de cada sociedad. Se trata de un mundo a pequeña escala de interacciones diarias y cara a cara por medio de las cuales, con el tiempo, los desconocidos llegan a confiar los unos en los otros, se hacen favores, aprenden a aceptar las diferencias de cada cual y, en ocasiones, cuando sobreviene la desgracia, muestran su resiliencia uniéndose".

Llegados aquí se plantean dos problemas: i) la producción colectiva de fidelidades múltiples, dicho de otra manera, la construcción colectiva de la interdependencia política; ii) la creación de marcos políticos capaces de aunar experiencias desiguales y transformar la interdependencia en la evidencia sociopolítica. El presente crea límites y permite nuevas conexiones entre naciones, estados y sociedades, por más que sigan buscándose formas políticas capaces de construir y organizar fidelidades múltiples y no exclusivas. Ni la nación, la postnacionalidad o la tradición niegan la mitología y las funciones del Estado-Nación, al contrario, la afirman en una nueva red ¿Hay acaso otro espacio para la afirmación nacional que no sea jugar con la red o hay otro lugar para la constelación cosmopolita que propugnarse permanentemente como sustituto funcional de la nación cuando ésta no sólo no desaparece sino que es la idiosincrasia simbólica del referente del presente, es decir, las de aquellas realidades que las integran y las relacionan con otras?

\section{BIBLIOGRAFÍA}

BAUMAN, Z. (2001): La Posmodernidad y sus descontentos. Madrid: Akal.

BAUMAN, Z.; BORDONI, C. (2016): Estado de crisis. Barcelona: Paidós.

BELLAH, R. N. (Coord.) (1989): Hábitos del corazón. Madrid: Alianza.

BILLIG. M. (2014): Nacionalismo Banal. Madrid. Capitán Swing.

BOYM, S. (2015): El Futuro de la Nostalgia. Madrid: Antonio Machado.

DEATON, A. (2016): El gran escape: Salud, riqueza y los orígenes de la desigualdad. México D.F.: Fondo de Cultura Económica. 
DIAMOND, J. (2006): Colapso: Por qué unas sociedades perduran y otras desaparecen. Barcelona: Debate.

FERGUSSON, N. (2018): La plaza y la torre: El papel oculto de las redes en la historia: de los Masones a Facebook. Barcelona: Debate.

GEERTZ, C. (2002): Reflexiones antropológicas sobre temas filosóficos. Barcelona Paidós.

GRAY, J. (2001): Las dos caras del Liberalismo: Una nueva interpretación de la tolerancia liberal. Barcelona: Paidós.

GREENFELD, L. (2016). Pensar con libertad: La humanidad y la nación en todos sus estados. Barcelona. Arpa.

IGNATIEFF, M. (2018): Virtudes cotidianas: Orden moral en un mundo dividido. Madrid. Taurus.

KHANNA, P. (2016): Conectografía: Mapear el futuro de la civilización mundial. Barcelona: Paidós.

KUAN YEW, L. (2015): The Singapore story: Memoirs of Lee Kuan Yew. Singapore: Singapore Press.

LILLA, M. (2004): Pensadores temerarios: Los intelectuales en la política. Barcelona: Debate.

-- (2017): La mente naufragada: Reacción política y nostalgia moderna. Barcelona: Debate.

-- (2018): El regreso Liberal: Más allá de la política de la identidad. Barcelona: Debate.

LUHMANN. N (1993): Teoría política del Estado del bienestar. Madrid: Alianza.

MANN, M. (2000): “¿Ha terminado la globalización con el imparable ascenso del Estado nacional?" Zona Abierta, 92/93: 175-212.

MAHBUBANI, K. (2002): ¿Pueden pensar los asiáticos? México D.F.: Siglo XXI.

MICKLETHWAIT, J. y WOOLDRIDGE, A. (2015): La cuarta revolución: La carrera global por reinventar el Estado. Barcelona: Galaxia Gutenberg.

MOROZOV, E. (2018): Capitalismo Big-Tech: ¿Welfare o neofeudalismo digital?. Madrid. Enclave de Libros.

MORETTI, E. (2012): The new geography of jobs. Boston: Houghton Mifflin Harcourt. 
MOUNK, Y. (2018): El pueblo contra la democracia: Por qué nuestra libertad está en peligro y cómo salvarla. Barcelona: Paidós.

PIPITONE, U. (2003): Ciudades, naciones, regiones: Los espacios institucionales de la modernidad. México: Fondo de Cultura Económica.

RODRIK, D. (2011): Una economía, muchas recetas: La globalización, las instituciones y el crecimiento económico. México D.F.: Fondo de Cultura Económica.

-- (2012): La paradoja de la globalización: Democracia y el futuro de la economía mundial. Barcelona: Antoni Bosch.

ROKKAN, S (2018): El Estado, la Nación y la Democracia en Europa: la teoría de Stein Rokkan. Madrid: CIS

SCHWAB, K. (2016): La cuarta revolución industrial. Barcelona: Debate.

SENNET, R. (1998): La corrosión del carácter: Las consecuencias personales del trabajo en el nuevo capitalismo. Barcelona: Anagrama

SHILS, E. (1982): The Constitution of Society. Chicago: The University. Chicago Press.

STREECK, W. (2016): Comprando tiempo: La crisis pospuesta del capitalismo democrático. Buenos Aires: Katz.

TAMBIAH, S. J. (1996): Buddhism betrayed?: Religion, politics, and violence in Sri Lanka. Chicago: University of Chicago Press.

TAYLOR, C. (1978): Las fuentes del yo: La construcción de la identidad moderna. Barcelona: Paidós.

-- (1993): El multiculturalismo y la política del reconocimiento. México: Fondo de Cultura Económica.

WALZER, M. (1996): Moralidad en el ámbito local e internacional. Madrid: Alianza.

WEI-MING, T. (ed.) (1996): Confucian traditions in East Asian modernity: Moral education and economic culture in Japan and the four mini-dragons. Cambridge: Harvard University Press. 
Ander Gurrutxaga Abad (Barakaldo, Bizkaia, 1956) es, desde 1994, Catedrático de Sociología de la UPV/EHU. Entre los libros que ha escrito destacan los siguientes: El Código Nacionalista Vasco durante el Franquismo (1985); La Refundación del Nacionalismo Vasco (1990) Las Paradojas Sociológicas (1996); La Mirada Difusa (2002); El Presente del Estado-Nación (ed.) (2004); La Producción de la Idea del Nosotros (2005); Recorridos por el Cambio, la Innovación y la Incertidumbre (2010); La Luz de la Luciérnaga. Diálogos sobre Innovación Social con Javier Echeverria (2012); Societies and Social Innovation (2013); Voces y Argumentos de la Innovación Social (2013); Fábricas del Futuro, con Auxkin Galarraga (2017); Rutas Nacionalistas (2017); Mapas del Cambio, con Auxkin Galarraga (2017). Ha dirigido, como investigador principal, veintiocho proyectos de investigación, nacionales e internacionales. Como profesor invitado ha impartido cursos, seminarios y conferencias en universidades extranjeras y españolas tales como California-San Diego-, Tel Aviv, Universidad Nacional Santo Domingo, Universidad de Cuzco, Universidad Veracruzana en VeracruzMéxico, Universidad de Duke, Complutense de Madrid, Autónoma de Barcelona, Universidad de Granada y Universidad Pública de Navarra. Ha dirigido/dirige más de veinte tesis doctorales. 